\title{
Diseño de un MOdelo PARA LA Optimización de los Procesos en el mantenimiento programado aplicado al equipo Casa 212 de la Fuerza Aérea Colombiana
}

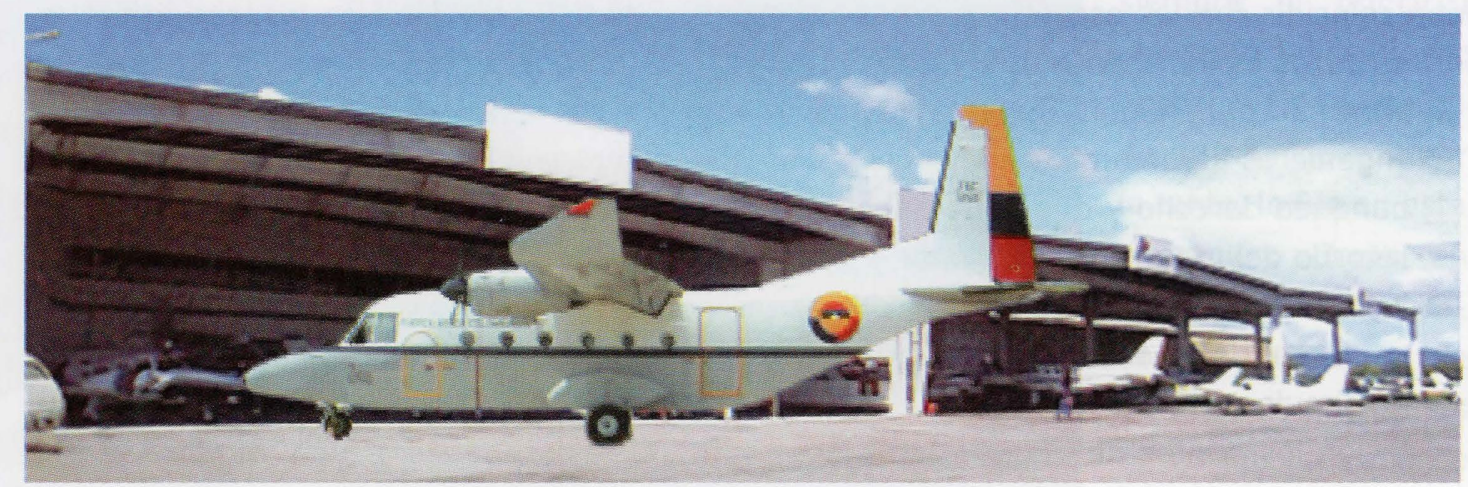

Este proyecto es el resultado de la bús-

Equeda constante de un mejoramiento continuo de los procesos que garantizan la calidad total en el mantenimiento

\section{IDENTIFICACIÓN GENERAL DEL PROYECTO}

$\begin{array}{ll}\text { PROGRAMA } & \text { ESPECIALIZACIÓN EN LOGÍSTICA } \\ & \text { AERONÁUTICA } \\ \text { TÍTULO } & \text { DISEÑO DE UN MODELO PARA LA } \\ & \text { OPTIMIZACIÓN DE LOS PROCESOS } \\ & \text { EN EL MANTENIMIENTO PROGRA- } \\ & \text { MADO APLICADO AL EQUIPO CASA } \\ & \text { 212 DE LA FUERZA AEREA COLOM- } \\ & \text { BIANA }\end{array}$

AUTORES MY.JOSE ENRIQUE SARMIENTO MY. MARIO ALEJANDRO ESPINOSA CT. HALVER YECID SANTOS

LÍNEA DE ESTRUCTURA AERONÁUTICA DE INVESTIGACIÓN MATERIALES

ÁREA FUNCIONAL aeronáutico, concebido y desarrollado para ser aplicado en el mantenimiento básico de 100 horas $0 \quad 1 \mathrm{~A}$ del equipo c-212-300 asignado al grupo técnico del Comando Aéreo de Combate No.2. Es así como se hace un recuento acerca de la historia y la evolución del mantenimiento aeronáutico, la normatividad y los métodos de trabajo, el estudio de tiempos y movimientos empleados actualmente, para garantizar la eficiencia y seguridad en la aviación comercial y mi- litar. De ahí, que se visitó la Base Aérea del Ejército del Aire Español, SATENA y la Base Aérea de Apiay de la Fuerza Aérea Colombiana, quienes tienen dentro de sus flotas el equipo C-212.

Esta investigación permitió identificar las fortalezas y falencias en el modelo de mantenimiento aplicado actualmente por la FAC, motivo por el cual la propuesta consta de una guía cuyo contenido describe de forma secuencial y lógica los procedimientos a seguir antes, durante y después de la aplicación de los requisitos de inspección en el mantenimiento programado del equipo C-212-300, de tal manera que en la guía se describen las funciones y procedimientos con diagramas de flujo, un paquete de inspección de mantenimiento programado por fase donde se desarrolla un ejemplo con la fase $1 \mathrm{~A}$ de 100 horas de vuelo para el equipo C-212-300 con la descripción de actividades, horas hombres y recursos, un sistema de información desarrollado en el lenguaje de programación MS.NET y con la base de datos MS_ACCESS para la administración del paquete de inspección de mantenimiento programado, y un manual del usuario que indica de manera fácil el manejo del sistema. 